\title{
Comportamento suíno influenciado por dois modelos de maternidade
}

\author{
Luana A. Sabino', Vilmar R. de Sousa Júnior ${ }^{1}$, Paulo G. de Abreu², \\ Valéria M. N. Abreu ${ }^{2}$, Letícia dos S. Lopes ${ }^{2} \&$ Arlei Coldebella ${ }^{2}$
}

\begin{abstract}
RESUMO
Neste estudo foram avaliados dois modelos de maternidade. O modelo um (MOD 1) era formado por duas salas similares, cada sala composta de oito celas parideiras individuais. O escamoteador era de alvenaria com tampa de madeira e aquecimento no piso, por resistência elétrica. A sala do modelo dois (MOD 2), continha 20 celas parideiras individuais, dentre as quais foram avaliadas apenas 16 . Os escamoteadores eram de madeira com aquecimento por lâmpada incandescente de $60 \mathrm{~W}$. Foram avaliadas as condições de ambiente das salas e do interior dos escamoteadores. O comportamento dos leitões foi avaliado no ambiente das salas e nos escamoteadores. O ambiente mais favorável para os leitões foi no MOD $1 \mathrm{com}$ o maior percentual de valores de temperatura e umidade dentro da zona de conforto. A temperatura do piso do escamoteador do MOD 2 obteve os melhores resultados. O comportamento mais observado nos leitões foi o de permanecerem no interior do escamoteador e deitados aglomerado. A presente área de estudo carece de mais pesquisas que levem em consideração variáveis que possam afetar a temperatura no interior dos escamoteadores, como o material utilizado na construção dos abrigos e a troca de calor entre os leitões.
\end{abstract}

Palavras-chave: ambiente, escamoteador, leitão

\section{Swine behavior in two motherhood models}

\begin{abstract}
In this study two models of motherhood were evaluated. A model (MOD 1) consisted of two similar rooms, each room was made up of eight individual breed cells. The creep was of brick with wooden lid and floor heating by electrical resistance. The rooms of second model (MOD 2), consisted of 20 individual cells breeder, where only 16 were evaluated. The creep of wood was heated by $60 \mathrm{~W}$ incandescent lamp. The environmental conditions of the rooms and the interior of creep were assessed. The behavior of the piglets was assessed in the hall environment and creep. Generally, the more favorable environment for the piglets was in MOD 1 with the higher values of temperature and humidity within the comfort zone. The floor temperature of creep of MOD 2 was the one which provided the best results. The most observed behavior in the piglets was to stay inside the creep area and cluster of lying. The theme of this study needs further research, taking into account variables that may affect the temperature inside the creep area such as the material used in construction of shelter and heat exchange among the piglets.
\end{abstract}

Key words: environment, creep, piglet

\footnotetext{
Universidade Federal dos Vales do Jequitinhonha e Mucuri (UFVJM). Bolsista CNPq. Rodovia MGT 367 - Km 583 no 5000 - Alto da Jacuba, CEP 39100-000 Diamantina, MG. Fone: (38) 3532-1200. E-mail: luana as@hotmail.com; sousajunior.vilmar@gmail.com

${ }^{2}$ Embrapa Suínos e Aves, BR 153, KM 110, CEP 89700-000 Concórdia, SC. Fax (49) 3441.0497. Fone: (49) 3441-0400. E-mail: pabreu@cnpsa.embrapa.br; valeria@cnpsa.embrapa.br; leticia@cnpsa.embrapa.br; arlei@cnpsa.embrapa.br
} 


\section{INTRODUÇÃO}

O bem-estar animal pode ser considerado uma demanda para que um sistema seja defensável eticamente e aceitável socialmente. As pessoas desejam comer carne com "qualidade ética", isto é, carne oriunda de animais que foram criados, tratados e abatidos em sistemas que promovam seu bem-estar e que sejam sustentáveis e ambientalmente corretos (Vercoe et al., 2000; Fraser, 2001).

A suinocultura é realizada de maneira escalonada com pequena margem de lucro, não se levando em consideração a atenção individualizada aos animais. O sofrimento dos mesmos pode resultar de privação física ou psicológica no confinamento, tais como: ausência de espaço, isolamento social e impossibilidade de se movimentarem, dentre outros (Campos et al., 2009).

Existem vários desafios dentro do ambiente de um animal, que podem causar pressão sobre ele, como sua condição de bem-estar (Johnson \& Mcglone, 2007). Também têm sido documentadas, na literatura, as necessidades de observação comportamental, incluindo a vocalização. Suínos vocalizam em várias situações e sua expressão vocal é citada como padrão de reconhecimento de estado de bem-estar, frustração ou sofrimento (Marx et al., 2003; Sampaio et al., 2005; 2007).

Com a crescente demanda do bem-estar animal por países compradores de carne suína, faz-se necessário a padronização de conceitos e normas, bem como análise crítica de todas as abordagens deste problema (Yeates \& Main, 2008). Por outro lado, estabelecer formas de se medir o bem-estar tem sido um tema controverso internacionalmente (Passilé \& Rushen, 2005). São oportunos estudos sobre o assunto, através de metodologias específicas, relacionados com a produtividade, em todas as fases da criação de suínos, buscando-se o melhor resultado econômico.

O comportamento é uma maneira dos animais demonstrarem o conforto ou o desconforto em relação ao ambiente. A avaliação desse comportamento é, hoje, normalmente realizada por meio de análise de imagem. Esta avaliação e os controles interativos do conforto térmico dos suínos pela análise de imagem, superam os problemas inerentes ao método convencional de observação visto que utilizam os próprios animais como biossensores, em resposta aos reflexos do ambiente por meio do estudo comportamental (Silva et al., 2004), reduzindo a interferência externa nos resultados observados. Desta forma objetivou-se, com este trabalho, avaliar o efeito de dois tipos de escamoteadores sobre o comportamento de leitões, do nascimento ao desmame.

\section{Material e MÉTODOS}

O experimento foi realizado em uma granja comercial localizada no município de Ipira, Estado de Santa Catarina, com latitude de $27^{\circ} 24^{\prime} 37^{\prime \prime} \mathrm{S}$ e longitude de $51^{\circ} 46^{\prime} 54^{\prime} \mathrm{O}$, no período entre 18 de julho a 18 de agosto de 2009. A propriedade, denominada unidade produtora de leitão (UPL), possui capacidade para alojar 150 matrizes, divididas em cinco salas.
O presente projeto foi submetido à apreciação da Comissão de Ética no Uso de Animais da Embrapa Suínos e Aves (CEUA/ CNPSA), sob o protocolo 011/09, tendo-se considerado aprovado e liberada sua execução, desde que respeitada a descrição da metodologia apresentada ao CEUA.

Os animais utilizados eram híbridos, linhagem Agroceres C23. Foram utilizadas três salas de maternidade. O modelo um (MOD 1) era formado por duas salas similares, sendo que cada sala era composta por oito celas parideiras individuais. A sala possuía 9,0 m de comprimento, 11,34 $\mathrm{m}$ de largura e pé direito de 3,0 m. A ventilação natural foi controlada por meio de cortinas nas laterais da sala. O piso das celas era de alvenaria semirripado, em que a parte ripada se localizava no terço final da cela, para o escoamento dos dejetos. A cela possuía 2,28 m de comprimento e 1,91 de largura e cada área de escape dos leitões era de $0,70 \mathrm{~m}$ de largura e a área de repouso da matriz continha $0,60 \mathrm{~m}$ de largura. $\mathrm{O}$ escamoteador era de alvenaria com dimensões de $0,97 \mathrm{~m}$ de comprimento, $0,70 \mathrm{~m}$ de largura e 0,62 $\mathrm{m}$ de altura com tampa de madeira. $\mathrm{O}$ aquecimento foi realizado por meio de resistência elétrica embutida no piso, controlado por termostato e iluminação por lâmpada fluorescente de $7 \mathrm{~W}$.

A sala do modelo dois (MOD 2), era composta por 20 celas parideiras individuais divididas em quatro linhas com cinco celas cada uma, mas somente 16 celas foram avaliadas. Amedida da sala era de 16,80 m de comprimento, 11,34 m largura e pé direito de $3 \mathrm{~m}$. As celas possuíam piso suspenso ripado em ferro com $5 / 8$ de polegadas, comprimento de $2,28 \mathrm{~m}$, tendo a área de repouso para a matriz $0,70 \mathrm{~m}$ de largura e as áreas de escape dos leitões $0,43 \mathrm{~m}$ de largura. Os escamoteadores eram de madeira com dimensões de 0,96 m de comprimento, $0,62 \mathrm{~m}$ de largura e $0,52 \mathrm{~m}$ de altura. $\mathrm{O}$ aquecimento era realizado com lâmpadas incandescentes de $60 \mathrm{~W}$. Da mesma forma que o MOD 1, o controle de ventilação foi realizado por meio de cortinas nas laterais da sala. As matrizes foram alojadas nas celas da maternidade dos dois modelos, dois dias antes da data prevista para o parto. A ordem de parto variou de um a cinco sendo distribuídas igualmente entre os dois modelos do experimento.

Nos escamoteadores do MOD 1 com aquecimento embutido no piso, os termostatos foram ajustados para $30^{\circ} \mathrm{C}$ do nascimento até o vigésimo primeiro dia e $25^{\circ} \mathrm{C}$ até o vigésimo sexto dia. Devido à logística de venda dos animais, alguns leitões foram vendidos antes de completarem os 28 dias de vida, idade comum para o desmame e, sendo assim, as análises foram realizadas até os 26 dia de vida.

Com a utilização de um termômetro infravermelho Mini Temp, com precisão de $\pm 2 \%$ e variação de -1 a $275^{\circ} \mathrm{C}$ foram coletadas as temperaturas do piso do escamoteador, uma vez por semana, em quatro horários, às 3, às 9 , às 15 e às 20 h.

Nas tampas dos escamoteadores, no centro geométrico de cada sala e no exterior das salas dentro de um abrigo meteorológico, foram instalados datalogger da marca TESTO ${ }^{\circledR}$ modelo T 175-2, para a coleta de temperatura de bulbo seco (Tbs) e umidade relativa do ar (UR), diariamente e a cada hora, durante o período experimental. Para a avaliação, na quarta semana, o MOD 2 apresentou duas celas desativadas nos últimos dias de experimento, em virtude da logística de venda 
dos animais, reduzindo a quantidade de dados apresentados no gráfico referente aos resultados desta análise.

O comportamento dos leitões foi avaliado por meio de análises de imagens. As imagens dos leitões foram capturadas com minicâmeras filmadoras NTSC infravermelho da marca CCTV modelo TM-004A, instaladas no interior do escamoteador, fixadas à tampa. As imagens foram adquiridas uma vez por semana, durante $24 \mathrm{~h}$ gerenciadas pelo programa Geovision GV800, sendo definidos para a filmagem os dias 0, 7, 14,21 e 26 de vida dos leitões. As análises das imagens dos leitões no interior dos escamoteadores foram realizadas em intervalos de cinco minutos, pausando o vídeo para verificar a frequência do comportamento dos mesmos no interior do escamoteador, segundo o etograma descrito a seguir:

Deitado aglomerado: quando os leitões estavam deitados
juntos
Deitado sozinho: quando o leitão estava deitado separado
dos outros
Interagindo: quando o leitão estava brincando ou brigando
com os outros

Para melhor entendimento quanto ao comportamento dos leitões analisados nas imagens do interior dos escamoteadores, calculou-se o percentual médio do número de leitões executando-se cada atividade analisada no período de $24 \mathrm{~h}$.

As imagens das baias foram monitoradas por meio de vídeocâmeras NTSC Sharp Modelo TI-012 infravermelha, instaladas em cima de cada cela. A análise foi realizada continuadamente, durante as $24 \mathrm{~h}$ de imagem de cada dia. Foi utilizado o etograma comportamental para avaliação da leitegada no ambiente da cela, como descrito a seguir:

Mamando: quando o leitão estava no teto da matriz Fora do escamoteador: quando o leitão estava fora do escamoteador e não caracterizava os outros comportamentos avaliados

Comendo: quando o leitão estava no comedouro

Bebendo: quando o leitão estava no bebedouro

Interagindo: quando o leitão estava brincando ou brigando com os outros

Os dados foram analisados por meio do modelo de medidas repetidas, utilizando-se o procedimento MIXED do SAS (2003), conforme Xavier (2000). Foram testados os efeitos de modelo, semana, horário e suas interações, considerando-se todos os efeitos fixos.

\section{Resultados E Discussões}

Verifica-se, na Tabela 1, que quando a temperatura foi medida no piso dos escamoteadores houve diferença significativa ( $p$ $<0,05)$ nas três primeiras semanas, sendo que o MOD 1 apresentou as maiores médias de temperatura.

Considerando as temperaturas de conforto (referência) para cada semana, conforme demonstrado na Tabela 2, só foram encontrados valores dentro da zona de conforto térmico na terceira semana de vida dos leitões, no MOD 2 (Tabela 1). Nas outras semanas os valores ora se apresentavam abaixo do recomendado como nas duas primeiras semanas, ora se apresentavam acima, como na quarta semana.

Tabela 1. Médias, erros-padrão e níveis descritivos de probabilidade do teste $\mathrm{F}$ por semana e horário para a temperatura do piso dos escamoteadores

\begin{tabular}{crrcr}
\hline \multirow{2}{*}{ Semana } & \multirow{2}{*}{ Horário } & \multicolumn{2}{c}{ Temperatura do piso do escamoteador $\left({ }^{\circ} \mathbf{C}\right)$} \\
\cline { 3 - 5 } & & MOD 1 & MOD 2 & Pr $>$ F \\
1 & 3 & $19,91 \pm 2,19$ & $14,88 \pm 0,55$ & 0,0003 \\
1 & 9 & $18,72 \pm 1,59$ & $15,53 \pm 0,26$ & 0,0034 \\
1 & 15 & $20,38 \pm 1,66$ & $14,53 \pm 0,54$ & $<0,0001$ \\
1 & 20 & $21,97 \pm 2,06$ & $16,53 \pm 0,43$ & $<0,0001$ \\
\hline 2 & 3 & $23,73 \pm 1,22$ & $19,21 \pm 0,82$ & 0,0013 \\
2 & 9 & $24,07 \pm 0,90$ & $17,78 \pm 0,65$ & $<0,0001$ \\
2 & 15 & $25,06 \pm 0,73$ & $19,75 \pm 0,75$ & $<0,0001$ \\
2 & 20 & $23,23 \pm 0,85$ & $18,70 \pm 0,82$ & 0,0016 \\
\hline 3 & 3 & $29,38 \pm 0,69$ & $24,15 \pm 1,12$ & 0,0006 \\
3 & 9 & $29,34 \pm 0,40$ & $21,15 \pm 1,06$ & $<0,0001$ \\
3 & 15 & $28,94 \pm 0,49$ & $24,18 \pm 1,01$ & 0,0002 \\
3 & 20 & $28,75 \pm 0,44$ & $24,60 \pm 1,13$ & 0,0029 \\
\hline 4 & 3 & $29,41 \pm 1,15$ & $28,95 \pm 0,32$ & 0,7721 \\
4 & 9 & $29,34 \pm 0,76$ & $27,08 \pm 0,48$ & 0,0678 \\
4 & 15 & $28,41 \pm 1,19$ & $26,98 \pm 0,54$ & 0,2758 \\
4 & 20 & $28,34 \pm 0,81$ & $25,93 \pm 0,51$ & 0,0951 \\
\hline
\end{tabular}

$\mathrm{p}<0,05$ diferem estatisticamente pelo teste $\mathrm{F}$

Tabela 2. Valores mínimos e máximos de temperatura e umidade do ar recomendados para cada semana de vida dos leitões

\begin{tabular}{cccccc}
\hline \multirow{2}{*}{$\begin{array}{c}\text { Idade } \\
\text { (semana) }\end{array}$} & \multicolumn{2}{c}{ Temperatura $\left({ }^{\circ} \mathbf{C}\right.$ ) } & & \multicolumn{2}{c}{ Umidade (\%) } \\
\cline { 2 - 3 } \cline { 5 - 6 } & Mínima & Máxima & & Mínima & Máxima \\
1 & 28 & 30 & & 50 & 70 \\
2 & 26 & 28 & & 50 & 70 \\
3 & 24 & 26 & & 50 & 70 \\
4 & 22 & 24 & & 50 & 70 \\
\hline
\end{tabular}

Fonte: Adaptado de vários autores

A temperatura do piso do escamoteador excessivamente quente pode ocasionar estresse térmico por calor, pois os animais no interior do abrigo normalmente ficam deitados, o que aumenta a troca de calor entre o animal e o piso, causando desconforto, reduzindo o tempo dos animais no interior do abrigo. Quando isto ocorre os leitões podem ficar expostos a condições de estresse por frio, quando então são acometidos por baixas temperaturas no ambiente externo. Isto pode trazer riscos aos leitões, pois eles podem procurar se aquecer junto ao úbere da porca, ficando expostos à área de esmagamento (Sobestiansky et al., 1998).

A análise dos dados de temperatura e da umidade relativa do ar obtidos pelos dataloggers no interior dos escamoteadores, foi realizada observando-se três regiões distintas, sendo a temperatura de conforto, acima da temperatura de conforto e abaixo da temperatura de conforto, com base nas temperaturas máximas e mínimas apresentadas na Tabela 2.

Conforme a Figura 1 e embora este trabalho apresente maiores resultados dentro da zona de conforto térmico durante o período experimental para o MOD 1 ( $\mathrm{p}>0,05)$, na primeira 

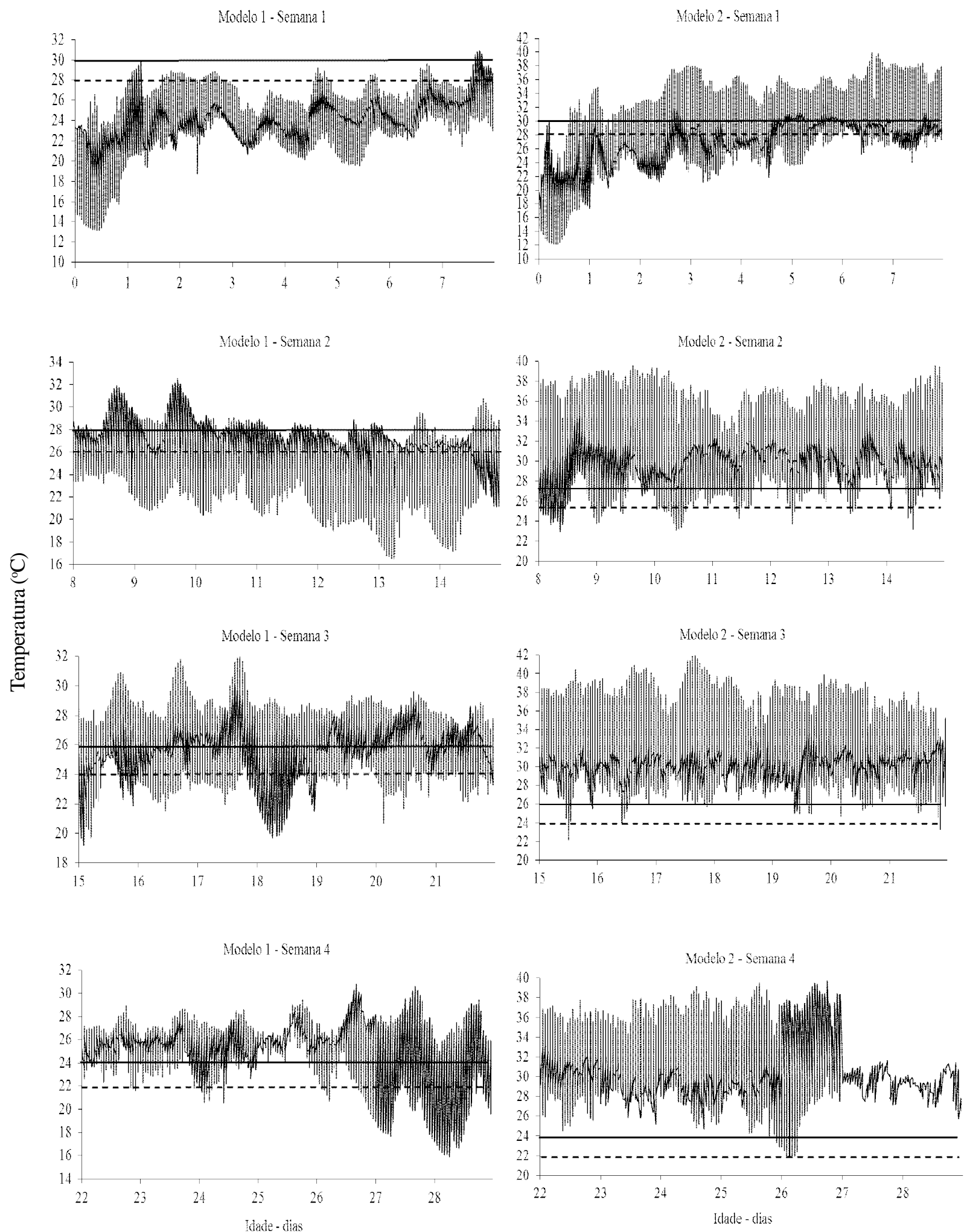

Figura 1. Distribuição dos dados de temperatura do ar no interior dos escamoteadores em cada modelo estudado durante cada semana do período experimental, em que a linha contínua representa a temperatura máxima e a linha tracejada, a temperatura mínima recomendada para cada semana de vida dos leitões

semana o MOD 2 mostrou-se melhor em relação ao MOD 1 para temperatura da sala. Esses resultados são similares aos encontrados por Pandorfi et al. (2005), em que o tratamento lâmpada incandescente apresentou-se melhor na primeira semana de vida dos leitões, na fase de maternidade.
Com a intenção de validar as informações obtidas acerca das variações de temperatura são apresentadas, na Tabela 3, as médias de temperatura no interior dos abrigos escamoteadores por semana e seu desvio padrão. 
Tabela 3. Percentual de dados, erros-padrão e níveis descritivos de probabilidade do teste $\mathrm{F}$ por semana da variável temperatura no interior dos escamoteadores

\begin{tabular}{|c|c|c|c|}
\hline Semana & Modelo 1 & Modelo 2 & $\operatorname{Pr}>\mathrm{F}$ \\
\hline \multicolumn{4}{|c|}{ Dentro da zona de conforto (\%) } \\
\hline 1 & $3,90 \pm 1,93$ & $26,04 \pm 3,89$ & $<0,0001$ \\
\hline 2 & $36,98 \pm 9,87$ & $14,21 \pm 4,22$ & 0,0250 \\
\hline 3 & $30,12 \pm 5,79$ & $1,86 \pm 0,66$ & $<0,0001$ \\
\hline 4 & $12,03 \pm 4,44$ & $0,52 \pm 0,52$ & 0,0019 \\
\hline \multicolumn{4}{|c|}{ Acima da zona de conforto (\%) } \\
\hline 1 & $0,26 \pm 0,26$ & $21,94 \pm 9,42$ & 0,0310 \\
\hline 2 & $12,28 \pm 6,14$ & $80,95 \pm 6,14$ & $<0,0001$ \\
\hline 3 & $54,80 \pm 10,6$ & $97,99 \pm 0,67$ & 0,0002 \\
\hline 4 & $81,85 \pm 7,39$ & $99,26 \pm 0,74$ & 0,0242 \\
\hline \multicolumn{4}{|c|}{ Abaixo da zona de conforto (\%) } \\
\hline 1 & $95,83 \pm 2,01$ & $52,02 \pm 7,46$ & $<0,0001$ \\
\hline 2 & $50,74 \pm 14,0$ & $4,83 \pm 2,23$ & 0,0064 \\
\hline 3 & $15,09 \pm 6,18$ & $0,14 \pm 0,09$ & 0,0176 \\
\hline 4 & $6,12 \pm 4,51$ & $0,22 \pm 0,22$ & 0,1107 \\
\hline
\end{tabular}

$p<0,05$ diferem estatisticamente pelo teste $F$

Embora o escamoteador do MOD 1 tenha apresentado as maiores temperaturas no piso, conforme apresentado na Tabela 1 , o calor gerado pelas placas de aquecimento não foi suficiente para aquecer o ar no interior do abrigo e promover uma condição confortável para os animais.

\section{Comportamento do leitão no ambiente das celas}

Verifica-se, na Figura 2 que, durante o período experimental, o tempo médio geral dos leitões "dentro do escamoteador" foi de $52,5 \%$ do tempo avaliado. Eles permaneceram $47,49 \%$ do tempo "fora do escamoteador", tempo este dividido em "mamando" $(33,77 \%)$, "outras atividades" $(18,28 \%)$, "interagindo" $(0,35 \%)$, "comendo" $(0,057 \%)$ e "bebendo" $(0,047 \%)$. Os resultados encontrados condizem com os resultados de Silva et al. (2005), em que a porcentagem de tempo dos leitões dentro do escamoteador foi maior do que o tempo fora do abrigo, independente do tratamento avaliado.

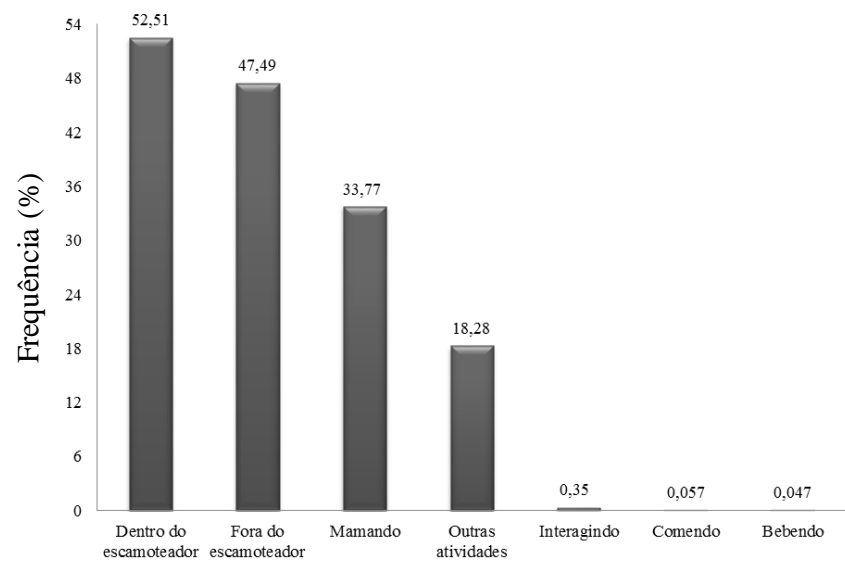

Figura 2. Frequência dos comportamentos dos leitões nas celas parideiras

Devido a interação semana $x$ modelo ter mostrado diferença significativa $(p<0,05)$ apenas na terceira semana para os comportamentos: dentro do escamoteador, fora do escamoteador, interagindo e fora do escamoteador - outras atividades, optou-se por trabalhar com as médias gerais dos modelos. Verifica-se, na Tabela 4, diferença estatística significativa $(\mathrm{p}<0,05)$ entre as médias gerais dos modelos em todo o período experimental, de todos os comportamentos avaliados, com exceção dos comportamentos "comendo", "bebendo"e "mamando".

Em geral, os leitões permaneceram mais tempo dentro do escamoteador equipado com lâmpada incandescente (MOD 2). Esses resultados diferem dos encontrados por Pandorfi et al. (2005), uma vez que os leitões permaneceram mais tempo nos abrigos escamoteadores equipados com piso térmico, seguidos por resistência elétrica, lâmpada incandescente e lâmpada infravermelha, respectivamente.

Tabela 4. Médias, erros-padrão e níveis descritivos de probabilidade do teste $\mathrm{F}$ por semana para o percentual de tempo de cada comportamento do leitão

\begin{tabular}{|c|c|c|c|}
\hline \multirow{2}{*}{ Semana } & \multicolumn{2}{|c|}{ Modelos } & \multirow{2}{*}{$\operatorname{Pr}>\mathrm{F}$} \\
\hline & Modelo 1 & Modelo 2 & \\
\hline \multicolumn{4}{|c|}{ Dentro do escamoteador (\%) } \\
\hline 1 & $56,45 \pm 6,09$ & $56,83 \pm 4,44$ & 0,9287 \\
\hline 2 & $40,79 \pm 6,71$ & $45,78 \pm 3,99$ & 0,0610 \\
\hline 3 & $32,64 \pm 3,92$ & $59,01 \pm 5,75$ & 0,0053 \\
\hline 4 & $36,74 \pm 11,1$ & $52,10 \pm 5,97$ & 0,1628 \\
\hline Média geral & $41,85 \pm 3,81$ & $53,13 \pm 2,52$ & 0,0043 \\
\hline \multicolumn{4}{|c|}{ Fora do escamoteador (\%) } \\
\hline 1 & $43,55 \pm 6,09$ & $43,17 \pm 4,44$ & 0,9287 \\
\hline 2 & $59,21 \pm 6,71$ & $54,22 \pm 3,99$ & 0,0610 \\
\hline 3 & $67,36 \pm 3,92$ & $40,99 \pm 5,75$ & 0,0053 \\
\hline 4 & $63,26 \pm 11,1$ & $47,90 \pm 5,97$ & 0,1628 \\
\hline Média geral & $58,15 \pm 3,81$ & $46,87 \pm 2,52$ & 0,0043 \\
\hline \multicolumn{4}{|c|}{ Interagindo (\%) } \\
\hline 1 & $0,667 \pm 0,407$ & $0,056 \pm 0,031$ & 0,1443 \\
\hline 2 & $0,485 \pm 0,227$ & $0,410 \pm 0,147$ & 0,7828 \\
\hline 3 & $0,654 \pm 0,182$ & $0,262 \pm 0,188$ & 0,0196 \\
\hline 4 & $0,095 \pm 0,046$ & $0,180 \pm 0,078$ & 0,4981 \\
\hline Média geral & $0,488 \pm 0,131$ & $0,228 \pm 0,063$ & 0,0229 \\
\hline \multicolumn{4}{|c|}{ Bebendo (\%) } \\
\hline 1 & $0,036 \pm 0,012$ & $0,063 \pm 0,039$ & 0,4224 \\
\hline 2 & $0,052 \pm 0,020$ & $0,033 \pm 0,013$ & 0,5971 \\
\hline 3 & $0,059 \pm 0,020$ & $0,045 \pm 0,031$ & 0,7230 \\
\hline 4 & $0,024 \pm 0,007$ & $0,066 \pm 0,036$ & 0,2879 \\
\hline Média geral & $0,043 \pm 0,008$ & $0,051 \pm 0,015$ & 0,5801 \\
\hline \multicolumn{4}{|c|}{ Comendo (\%) } \\
\hline 1 & $0,000 \pm 0,000$ & $0,000 \pm 0,000$ & 0,3861 \\
\hline 2 & $0,002 \pm 0,001$ & $0,042 \pm 0,016$ & 0,0281 \\
\hline 3 & $0,108 \pm 0,040$ & $0,130 \pm 0,061$ & 0,7342 \\
\hline 4 & $0,080 \pm 0,043$ & $0,128 \pm 0,067$ & 0,3542 \\
\hline Média geral & $0,048 \pm 0,016$ & $0,067 \pm 0,021$ & 0,2344 \\
\hline \multicolumn{4}{|c|}{ Mamando (\%) } \\
\hline 1 & $30,02 \pm 3,89$ & $32,84 \pm 3,25$ & 0,6585 \\
\hline 2 & $35,30 \pm 6,21$ & $38,05 \pm 2,32$ & 0,6760 \\
\hline 3 & $41,85 \pm 4,49$ & $26,69 \pm 3,65$ & 0,0596 \\
\hline 4 & $34,10 \pm 6,76$ & $28,96 \pm 4,15$ & 0,4739 \\
\hline Média geral & $35,36 \pm 2,64$ & $32,18 \pm 1,76$ & 0,2560 \\
\hline \multicolumn{4}{|c|}{ Fora do escamoteador - outras atividades (\%) } \\
\hline 1 & $12,82 \pm 2,81$ & $10,21 \pm 2,03$ & 0,3609 \\
\hline 2 & $23,35 \pm 5,90$ & $15,68 \pm 2,24$ & 0,0745 \\
\hline 3 & $24,69 \pm 2,67$ & $13,86 \pm 2,08$ & 0,0134 \\
\hline 4 & $28,97 \pm 7,96$ & $18,57 \pm 3,52$ & 0,2433 \\
\hline Média geral & $22,21 \pm 2,64$ & $14,35 \pm 1,30$ & 0,0054 \\
\hline
\end{tabular}

$\mathrm{p}<0,05$ diferem estatisticamente pelo teste $\mathrm{F}$ 
Xin \& Zhang (1999) encontraram resultados semelhantes aos de Pandorfi et al. (2005), quando estudaram a preferência dos leitões por lâmpadas de aquecimento ou por pisos térmicos, quando submetidos a diferentes condições ambientais. Os autores revelaram que, de maneira geral, o piso térmico foi preferido pelos leitões.

Uma provável explicação para esta diferença seria que nos experimentos citados acima de Pandorfi et al. (2005) e Xin \& Zhang (1999), as lâmpadas incandescentes utilizadas eram de potência maior $(200 \mathrm{~W})$ do que as utilizadas no presente estudo $(60 \mathrm{~W})$.

Uma das vantagens do aquecimento por superfície é promover uma temperatura mais uniforme na área de descanso do suíno do que o aquecimento por energia radiante (lâmpadas), devido ao processo de condução piso-leitão, como pode ser observado nas pesquisas realizadas por Zhang \& Xin (2001); porém, se a temperatura estiver muito elevada os leitões tendem a ficar menos tempo neste ambiente. Corroborando com esta observação, os animais do MOD 1 permaneceram mais tempo fora do escamoteador.

Fora do escamoteador foi observado, também, que os animais exerciam outras atividades, encontrando-se diferenças nas segunda e terceira semanas $(\mathrm{p}<0,05)$ e, de maneira geral, essas atividades tinham maior porcentagem no MOD 1 já que neste tratamento o tempo dos animais fora do abrigo escamoteador era maior.

No comportamento interagindo só foram encontradas diferenças na terceira semana e novamente com maiores resultados no MOD 1, provavelmente em decorrência das altas temperaturas dentro do escamoteador, que faziam com os esses animais permanecessem fora do abrigo, em atividade com outros leitões.

\section{Comportamento do leitão no interior do escamoteador}

Verifica-se, na Tabela 5, que não houve nenhum efeito significativo para o percentual médio de leitões, em cada comportamento avaliado $(\mathrm{p}<0,05)$.

Tabela 5. Níveis descritivos de probabilidade do teste $F$ da análise de modelos mistos para medidas repetidas para o percentual médio do número de leitões em cada atividade analisada para o leitão no escamoteador

\begin{tabular}{lrcc}
\hline \multirow{2}{*}{ Variável } & \multicolumn{3}{c}{ Pr $>$ F } \\
\cline { 2 - 4 } & Modelo & Semana & Modelo $\times$ Semana \\
Deitado aglomerado & 0,0978 & 0,6137 & 0,1194 \\
Deitado sozinho & 0,1169 & 0,1281 & 0,4812 \\
Em pé & 0,1481 & 0,2328 & 0,0626 \\
Interagindo & 0,5615 & 0,3400 & 0,3081 \\
\hline p $<0,05$ dffren
\end{tabular}

O percentual médio mais frequente foi o "deitar aglomerado", seguido do "deitado sozinho", "em pé" e "interagindo", respectivamente (Figura 3).

Observou-se, ainda, que a maior média geral do número de leitões nos dois modelos foi o comportamento de "deitar aglomerado" (Figura 3).

O tema do presente estudo necessita de mais pesquisas que levem em consideração outras variáveis passíveis de afetar

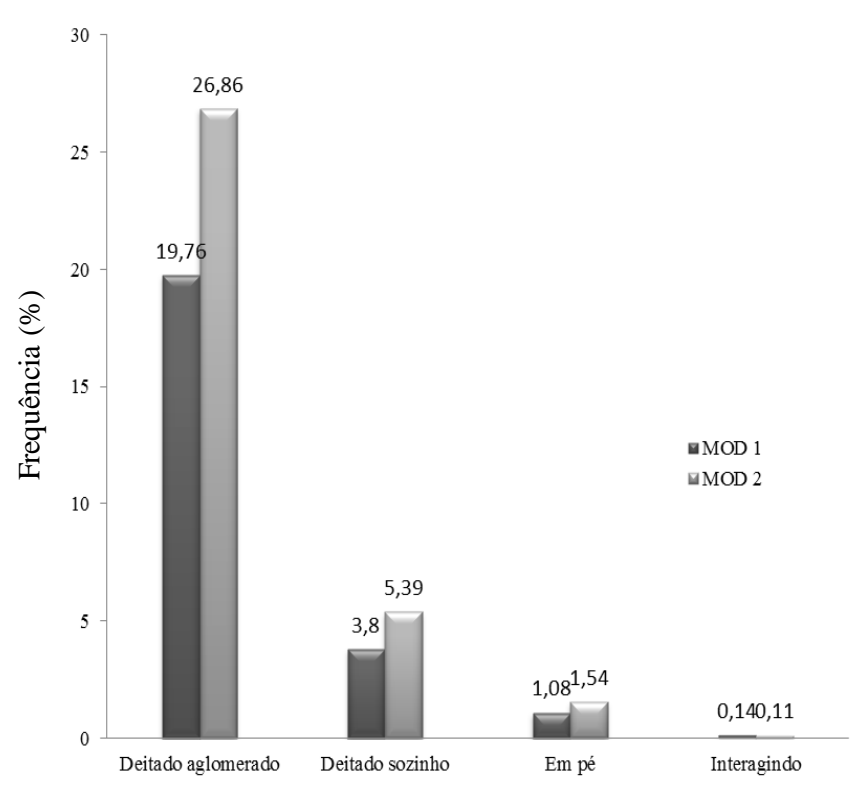

Figura 3. Percentual do número de leitões com cada comportamento avaliado nos dois sistemas

a temperatura dentro dos abrigos escamoteadores, como o material utilizado na construção dos escamoteadores e a troca de calor entre os animais.

\section{ConClusõES}

1. Os dois escamoteadores foram deficientes quanto à temperatura adequada para as quatro semanas de vida dos leitões. Embora não seja ideal, o escamoteador com aquecimento por lâmpada incandescente mostrou-se melhor em relação ao escamoteador com aquecimento no piso em relação à temperatura do abrigo.

2. O comportamento dos leitões no interior do escamoteador que apresentou maior frequência foi o de deitar aglomerado.

3. No ambiente das celas o comportamento dos leitões que apresentou maior frequência foi o de ficar dentro do abrigo escamoteador, nas primeiras semanas vida.

\section{LITERATURA CITADA}

Campos, J. A.; Tinôco, I. de F. F.; Baêta, F. C.; Cecon, P. R.; Mauri, A. L. Qualidade do ar, ambiente térmico e desempenho de suínos criados em creches com dimensões diferentes. Engenharia Agrícola, v.29, p.339-347, 2009.

Fraser, D. The "new perception" of animal agriculture: legless cows, featherless chickens and a need for genuine analysis. Journal of Animal Science, v.79, p.634-641, 2001.

Johnson, J. L. S. S.; Mcglone, J. J. Making sense of apparently conflicting data: Stress and immunity in swine and cattle. Journal Animal Science, v.85, p.E81-E88, 2007.

Marx, G.; Horn, T.; Thielebein, J.; Knubel, B.; Borell, E. Von. Analysis of painrelated vocalization in young pigs. Journal of Sound and Vibration, v.266, p.687- 698, 2003. 
Pandorfi, H.; Silva I. J. O.; Moura, D. J.; Sevegnani, K. B. Microclima de abrigos escamoteadores para leitões submetidos a diferentes sistemas de aquecimento no período de inverno. Revista Brasileira de Engenharia Agrícola e Ambiental, v.9, p.99-106, 2005.

Passillé, A. M.; Rushen, J. Can we measure human-animal interactions in on farm animal welfare assesment?: Some unresolved issues. Applied Animal Behaviour Science, North-Holland, v.92, p.193-209, 2005.

Sampaio, C. A. P.; Nääs, I. A.; Nader, A. Gases e ruídos em edificações para suínos: aplicação das normas NR-15, CIGR e ACGIH. Engenharia Agrícola, v.25, p.10-18. 2005.

Sampaio, C. A. P.; Nääs, I. A.; Salgado, D. D.; Baracho, M. S. Avaliação de poluentes aéreos em instalações de creche e terminação de suínos. Ciência Rural, v.37, p.488-494, 2007.

Silva, I. J. O.; Pandorfi, H.; Piedade, S. M. S. Uso da zootecnia de precisão na avaliação do comportamento de leitões lactentes submetidos a diferentes sistemas de aquecimento. Revista Brasileira de Zootecnia, v.34, p.220-229, 2005.

Silva, W. T.; Moura, D. J.; Nääs, I. A.; Mendes, A. S.; Lima, K. A. O. Estimativa de bem-estar de leitões utilizando a visão computacional. Revista Brasileira de Agroinformática, v.6, p.79-89, 2004.
Sobestiansky, J.; Moraes, N.; Wentz, I.; Moreno, A.M. Manejo do leitão desde o nascimento até o abate. In: Sobestiansky, J. R.; Wentz, I.; Silveira, P. R. S.; Seste, L. A. C. Suinocultura intensiva: produção, manejo e saúde do rebanho. Brasília: SPI; Concórdia: CNPSA, 1998. p.135-161.

Vercoe, J. E.; Fitzhugh, H. A.; Kaufmann, R. van. Livestock productions systems beyond Asian-Australian. Journal of Animal Sciences, v.13, p.411-419, 2000.

Xavier, L. H. Modelos univariado e multivariado para análise de medidas repetidas e verificação da acurácia do modelo univariado por meio de simulação. Piracicaba: ESALQ, 2000. 91p. Dissertação Mestrado

Xin, H.; Zhang, Q. Preference for lamp or mat heat by piglets at cool and warm ambient temperatures with low to high drafts. Applied Engineering in Agriculture, v.15, p.547-551, 1999.

Yeates, J.W.; Main, D.C.J. Assessment of positive welfare: A review. The Veterinary Journal, v.175, p.293-300, 2008.

Zhang, Q.; Xin, H. Responses of piglets to creep heat type and location in farrowing crate. Applied Engineering in Agriculture, v.17, p.515-519, 2001. 